\title{
Is Design Thinking, Really Thinking?: Designers in the 21st Century do not really think; they are in fact reactive decision makers!
}

\author{
Philip G. C. Whiting, Griffith University, Queensland, Australia
}

\begin{abstract}
Designers may believe they influence the outcome of a design including important environmental issues and sustainability to varying degrees as their thought process moves from rough concepts towards a final outcome, yet any design is already heavily influenced by the client and their perceived need(s) before the designer is even considered or approached. Design thinking begins with a brief and ends with an outcome whereby the designer is managing the process in between, however a key issue of design management is framed by whom or what is directing design and where the designer is placed in this play of forces as a compliant or resistant subject. How do designers think about themselves? Design suggests a thought process has taken place to address a problem and provide a creative solution or outcome. Does the term creative suggest a different approach to the thought process for the designer when in design mode and is creative thinking enough? If design is the link between art and science, where both borrow from nature then should design thinking not model itself on nature and therefore evolution or natural development? To achieve this designers have to become leaders and not service providers, they have to become reflective and creative thinkers, proactive and re-directive. Making critical design decisions that continuously question their role and responsibility at every level of design they must determine the real problem through solution risk mapping not the perceived problem and provide the optimum solution from every aspect of human behaviour through concept risk mapping and understand the future impact of the optimum solution through virtual risk mapping of the impact upon the environment or lack of and how the design fits into our overall lifestyles.
\end{abstract}

Keywords: Design Thinking, Creative Thinking, Design Management, Sustainability, Evolutionary Design

\section{Design Thinking}

TN MY ORIGINAL paper 'Changing the way designers think!' I introduced the notion that whilst designers may believe they positively influence a design and direct its development to achieve the best possible outcome at any point in time; in actual fact their design thinking is inherently flawed from the outset, as the designer is essentially a compliant force bringing limited resistance within the boundaries already established by others in terms of perceived needs and problems. In other words many important or critical decisions have already been decided with absolutely no reference to or input from a designer. Granted, designers will endeavour to re-direct their client by moving the proposed design towards a more suitable \& sustainable outcome, but even this is still framed within the parameters established by others involved in the process from the outset.

Whilst these parameters will be by their very nature, narrow and limited, it is still possible even with these constraints for a designer to expand outwards beyond these predetermined limitations in the search for better alternatives by re-writing the design brief in an effort to 
re-educate and re-direct the thinking of others. Designers would probably claim to do this on a regular basis, however even this process is both tainted and limited by a preconceived notion of the problem at hand and the required outcome that stems from this. Is this preconceived notion of the problem therefore not the real problem, but is in itself a perceived problem that distracts from the real problem, effectively negating any real design thinking?

In Heidegger's “What is called Thinking?', Lecture III he refers to "the many sidedness that may expand to such proportions that the one-sidedness on which it is based no longer catches our eye.". And so it may be with design thinking as designers strive to investigate multiple views of the perceived problem, they believe they are actually reviewing all possible options or scenarios. But if this perceived problem itself is flawed then designers are either only looking at part (or one side of the problem) and it is quite feasible that their attention has already been focused upon the wrong problem to begin with.

Any problem or question will provide food for thought and therefore could be considered as thinking however this thinking needs to begin by challenging the very nature of the perceived problem. As a simple example the perceived problem could be the need to travel from Australia to London, where the client has already decided that the best or most cost effective solution is to fly and the only options to be considered are flight availability, time and cost. The designer may still investigate other alternatives and even present strong arguments in favour of each alternative put forward, including Hot Air Balloon travel, ship/ferry \& car, drilling through the centre of the earth or space travel. Of course the critical question here is why the client needs to travel to London in the first place, what is it that they need to achieve when they arrive there and even question is London the most suitable destination/location?

For once we understand the real problem and what the underlying expectation is, a totally different range of alternatives present themselves, such a telephone call, a letter, a courier, a pigeon, the internet. By fully understanding the very nature of the real problem to be addressed or the expected outcome, we then provide food for further or deeper design thought.

In one sense this suggests the beginnings of a hierarchy of design thought, a preliminary thought process occurring here that could be managed, that needs to be addressed to ensure the designer is really thinking and not simply reacting to the decisions of others.

\section{Design Management}

In the same paper "Changing the way designers think!" I also introduced the concept of design 'thought' management and the notion that it is necessary to understand what it is to be managed in the first place and why; as opposed to what many designers understand by the term Design Management. If we accept that the underlying understanding of any form of management is to control (or manage) in such a way as to move things forward. To ensure that things happen in a timely and efficient manner and in turn to ensure that nothing critical or important is forgotten or left out, is considered at the appropriate time and place, designers could be forgiven as seeing what they do every day as the management of design or design management, when in fact it is rather a variation on project management or even design business management.

Here I am suggesting that in one sense management of the design process is in fact the management of the design thought process, yet this in itself at first sight seems an almost ambiguous or misleading statement. Surely if you try to manage thought, you effectively 
disarm and limit thinking, but what we are considering here is not control of actual thought, but the process, what needs to be thought about! Let me try to take this a little further. If design thinking begins with questioning what is actually trying to be achieved and why, it is important that the designer has the freedom to think creatively, but still ensure that this process covers all possibilities. This means that part of the role of design management should also be to question and challenge the very foundation of the perceived problem to fully understand what is the desired outcome or expectation required. In other words using the earlier example, why does the client need to go to London, is there a need to travel to London and will being in London provide the desired outcome or solution. This brings me back to current design thinking that begins with a brief and ends with an outcome, where if we accept that the nature of the brief is directly influenced by the perceived problem, then we have to ensure the problem has been clearly defined and correctly identified in the first place. If we now assume that this is the case, then the designer has to next ensure that every conceivable and possible option is considered. Of course at this point are we really functioning within the realm of 'traditional' thinking around a question or problem? Where it could be argued that traditional thinking can be seen as a logical progression of thought connecting one related thing with the next. If this is the case does it bring us back to one-sidedness of a problem, but also to a point at which a designer can introduce Creative Thinking as a vehicle to redirect or force the thought process from traditional \& logical thought into a different realm or higher level of thought? When, where and how should a designer introduce this creative thinking as opposed to traditional thinking? Is this where a design thought management process can provide the model for these different levels of thought to be introduced in a timely and efficient manner? If this is the case then design management in managing a total creative process has to take this on board.

Professor Rachel Cooper in the forward to Vision and Values in Design Management states that Design Management is a discipline in continual motion, changing, responding and adapting to the ever-increasing dynamics of social and business transformation (Hands, David 2009).

(Fry, Tony 2009) in his recent book Design Futuring has identified design as one of the key movers of change and argues for this to happen, the very foundation of design and designing has to be transformed in terms of how designers think about design and designing.

\section{Creative Thinking}

Heidegger (What is called Thinking?) in Lecture III also talks about ideas and I would begin to argue here that these could be considered the realm of the designer and design thinking, where ideas are simply preliminary thoughts or questions, but how do designers generate those ideas?

Is it not clearly understood that drawing as a mode of visual research provides the designer with a deeper understanding of the object being drawn, then to draw the same object from a range of distances, perspective views only adds to a greater or deeper understanding, however at the same time this visual research process also begins to raise other questions or thoughts within the thinking of a designer. The act of drawing creates food for thought; a thought-provoking visual analysis, it is a face-to-face meeting where the designer does much 
more than simply perceive it, they begin to formulate new ideas, make connections where none existed before, designers create possibilities to be explored, questioned, they create further food for thought from seemingly illogical and unconnected things.

If we accept that the whole point of design and the role of the designer is to challenge, question assumptions and to not assume anything, then creative thinking can be seen as the jurisdiction of the designer and the question becomes not what is creative thinking, but can creative thinking be seen as thought at a different, higher or deeper level of thinking?

Many different creative thinking strategies abound, forms of creative thinking to redirect the human brain, to effectively shift thinking from one-track or multi-track thinking around a problem and for many creative thinking will be simply seen as nothing more than the generation of ideas or $2 \mathrm{D}$ and $3 \mathrm{D}$ visual concepts that are pleasing to the eye. This only trivialises both the outcome and the process of creative thought that should reside in the realm of new and highly original thought. The generation of incredible ideas and rough concepts are those thoughts that have yet to be fully resolved and thereby made credible to the world at large.

Heidegger also states that a thinker is more essentially effective where he is opposed, than where he finds agreement and most designers would probably agree with that statement if applied to design, designers in their pursuit of original thought bring together two often opposing or contrasting thoughts and begin to find connections; could this be seen as the foundation of Creative Thinking? Is it the role of the designer to inhabit the middle ground between both Art and Science? Where Art is seen as the jurisdiction of the creative artist and Science is seen as the jurisdiction of the logical scientist and the designer can be seen as once more bringing together two opposing or contrasting elements to create a third outcome.

Can it also be argued that art and science are the very foundation of nature, where nature creates art through the visual interpretation of the natural environment and uses science to create structure, form and sustainability? Everything in nature has a reason for being, a purpose, an interconnectedness; from the tree itself in providing a habitat and shelter to its branches, leaves, seeds and root system. As the seasons change so the tree in part dies to be reborn again and the waste feeds back into the ground for further nourishment for the tree and other living creatures. At the same time the tree continues to grow until it will eventually die, whereupon it too feeds back into the system into which it is connected to. Whilst this is an essentially simplistic view of nature, it clearly demonstrates how nature designs the environment, not in isolation as designers may do, but within a highly connected system. Continually adjusting and improving those outcomes that work well and allowing those with no future to pass away. Is nature the ultimate designer creating the ultimate relationship between art and science?

\section{Sustainability and Evolutionary Design}

If Designers today are essentially short-term reactive thinkers; do they then only consider the immediate problem even when they believe they are considering the long term issues associated with the immediate problem? They may consider the immediate or short-term impact or side effects of their outcome and the process to produce it, but they do not consider the interconnectedness of the outcome, the other outcomes good or bad it may also spawn by its very existence. It could be argued here that designers do consider in one sense other opportunities for future outcomes or additions, yet still no real long term consideration both 
negative and positive is given to the process of production, the impact of the all the parts that make up the outcome and the outcome itself, it is still constrained by the control or limited thinking of others.

So what is design thinking? Is it the need to determine what it is that is trying to be achieved by the design and creation of the outcome in the first place, once this has been clearly established, is this the food for thought to enable the designer to begin to look at all the possible options including creative thinking, not for the design itself as such, but ways of arriving at the desired end result or expectation. Included in this process has to be thinking about the interconnectedness of each possibility at every stage or critical decision point.

This design thought process now begins to reflect what nature does and how it develops and evolves its design in a sustainable way. Nature is sustainable, left to its own resources without outside interference it continues to create a self-sufficient, sophisticated system and infrastructure that builds and evolves and life goes on, a balance.

We talk about controlling nature when we should perhaps be thinking in terms of managing nature for our needs, but this distracts from the main point of this paper. Should design thinking begin to try to emulate nature and evolve designs, this does not limit the possibility of the new, but it does redirect design thinking to consider every possible aspect including all production processes and designs from the past. To consider the interconnectedness of what they are doing today with what already exists, that could be adopted or adapted or reinvented for sustainable future.

Is the problem also how designers presently function and see themselves as part of a service industry and have become reactive decision makers because of this? Designers are pathfinders, providing direction, but its leadership is heavily compromised by its position and status. If designers are to become true leaders and improve not just the quality of life but the quality of the world for following generations they have to re-think design. Not in the isolation of short-term needs, but as part of a much greater inter-connected global system and how their particular outcome will impact upon that system. Should we now be moving towards a process of Evolutionary Design Thinking?

\section{References}

Best, Kathryn (2006) Design Management, Managing Design Strategy, Process and Implementation AVA Publishing, Switzerland ISBN 2940373124

Borja deMozota, B (2003) Design Management: Using design to build brand value and corporate innovation Allworth Press, New York

Fry, Tony (2009) Design Futuring, Sustainability, Ethics and New Practice University of New South Wales Press Ltd, Sydney Australia ISBN 9781921410840

Heidegger, Martin (Translated by J. Glenn Gray) (1968) What is called Thinking? Harper \& Row, New York. ISBN 0-06-090528-X1272

Whiting, Philip (2009) Changing the way designers think! DesignEd Asia Conference, Hong Kong www.sd.polyu.edu.hk/designconference2009 